\title{
SPECTROSCOPIC STUDIES OF POLYOXOMETALATES AND THEIR COMPLEXES WITH LANTHANIDE(III) IONS IN SOLUTION
}

\author{
S. LIS \\ Department of Rare Earths, Faculty of Chemistry, Adam Mickiewicz University \\ Grunwaldzka 6, 60-780 Poznań, Poland
}

The results of investigations related to physico-chemical properties, synthesis and structure of polyoxometalates and their lanthanide(III) complexes are briefly reviewed. Useful techniques for the verification of polyoxometalate compositions and the determination of components are compared. Complexation of metal ions, especially of lanthanide(III) ions, with polyoxometalates using absorption (in the UV-visible and the near IR region) and luminescence spectroscopy methods are presented. Absorption hypersensitive transitions of certain lanthanide(III) ions and laser-induced europium(III) ion luminescence spectroscopy are shown to be useful in complexation investigations. The significance of some polyoxometalate complexes as potential magnetic resonance imaging agents and in biological studies as antiviral agents are discussed.

PACS numbers: 42.62.IH, 78.40.-q, 78.40.Ha, 78.55.-m

\section{Introduction}

Chemistry of polyoxometalates (POMs) is an important subarea of modern inorganic chemistry. with wide applications in catalysis, oxidation chemistry, photochemistry, electron microscopy and as inorganic drugs [1,2]. While solution chemistry of metal oxides is generally limited due to solubility limitations, polyoxometalates are important exceptions that form a unique class of compounds of special properties. The insoluble metal oxides are composed of close packed arrangements of oxide ions which form infinite chains, sheets or three-dimensional lattices, whereas the polyoxometalates form discrete anions of high symmetry [3]. The potential analogy between the solution chemistry of large polyoxoanions and the solid state chemistry of the metal oxides have earned the former the designation of a "pseudo-liquid phase" [4]. These discrete polyanions are water soluble structures with charges ranging from -3 to -14 . The surface basicity is generally considered to be rather weak, with most of the charge concentrated on oxygen atoms below the surface [5]. In accord with low surface charge density, in the presence of appropriate counter ions, POMs are soluble in organic solvents ranging in polarity from dimethyl sulfoxide to benzene [6]. 


\section{Structure and synthesis}

The majority of POM structures has been categorized into three structural groups [7]. Groups 1 and 2 are characterized by a highly symmetrical assembly of $\mathrm{MO}_{6}$ octahedra (most commonly, $\mathrm{M}=\mathrm{Mo}(\mathrm{VI}), \mathrm{W}(\mathrm{VI})$; also $\mathrm{M}=\mathrm{V}(\mathrm{V}), \mathrm{Nb}(\mathrm{V})$ and $\mathrm{Ta}(\mathrm{V}))$ which surround a central core. For group 1 structures, the core is composed of one or two tetrahedra $\mathrm{XO}_{4}$ (where the heteroelement, $\mathrm{X}=\mathrm{B}(\mathrm{III}), \mathrm{P}(\mathrm{III}), \mathrm{Si}(\mathrm{IV})$, $\mathrm{Ge}(\mathrm{IV})$ ) whereas for group 2 structures, the central core is a transition metal octahedron $\mathrm{XO}_{6}$ (e.g. $\mathrm{X}=\mathrm{Mo}(\mathrm{VI}), \mathrm{Mn}(\mathrm{II})$ ). Group 3 structures are based on an icosahedrally coordinated central core. Examples of each structure are given in Table I.

\section{TABLE I}

Polyoxometalate structural group examples.

\begin{tabular}{c|c|c}
\hline $\begin{array}{c}\text { Group 1 } \\
\text { Tetrahedral core }\end{array}$ & $\begin{array}{c}\text { Group 2 } \\
\text { Octahedral core }\end{array}$ & $\begin{array}{c}\text { Group 3 } \\
\text { Icosahedral core }\end{array}$ \\
\hline $\mathrm{SiW}_{12} \mathrm{O}_{40}^{4-}$ & $\mathrm{Mn}^{\mathrm{II}} \mathrm{Mo}_{9} \mathrm{O}_{32}^{6-}$ & $\mathrm{Ce}^{\mathrm{VI}} \mathrm{Mo}_{12} \mathrm{O}_{42}^{8}$ \\
$\mathrm{P}_{2} \mathrm{~W}_{18} \mathrm{O}_{62}^{6-}$ & $\mathrm{Te}^{\mathrm{VI} \mathrm{Mo}_{6} \mathrm{O}_{24}^{6-}}$ &
\end{tabular}

The spherical-like structures of group 1 are called plenary structures (latin plenarius - full, complete) and their degraded derivatives are called lacunary structures (latin lacunar - gap, pit). The plenary structures are further categorized by the number of central ietrahedra, where the Keggin structure $\left(\mathrm{XM}_{12} \mathrm{O}_{40}^{n-}\right)$ and the Dawson $\left(\mathrm{X}_{2} \mathrm{M}_{18} \mathrm{O}_{62}^{m-}\right)$ structure have one and two central tetrahedra, respectively. When isolated as solids, both structures are highly hydrated with thermal gravimetric curves showing two steps which are characteristic of zeolitic water and waters of hydration [8]. In fact, no anhydrous polyoxo compounds are known. After calcination POMs return to a saturation level for absorbed water (e.g. the polyoxo acid, $\mathrm{II}_{3} \mathrm{PW}_{12} \mathrm{O}_{40}$, calcined at $250^{\circ} \mathrm{C}$ returned to hydration level of 27 to 30 molecules in only a few hours [9]).

The group 1 POM surfaces are defined by the external assembly of $\mathrm{MO}_{6}$ octahedra which are grouped in blocks of threes, termed triads, such as $\mathrm{M}_{3} \mathrm{O}_{13}$ [10]. While these plenary structures are known to be stable at $p H \sim 4.5$, they are unstable in the presence of $\mathrm{OII}^{-}$and degrade at higher $p H$ by loss $[\mathrm{MO}]^{4+}$ species forming various lacunary species. Controlled degradation by addition of a stoichiometric amount of base gives high yields of the daughter lacunary structure. The loss of one octahedral vertex, $[\mathrm{MO}]^{4+}$, gives the same quasi-spheroid shape of the parent but with a defect site and a larger formal anionic charge. These mono-defect lacunary structures (e.g. $\mathrm{PW}_{11} \mathrm{O}_{39}^{7-}$ ) are stable in aqueous solution between $p H 5$ and 8 [11].

Synthesis of POMs occurs by a remarkable self-assembly process governed by reaction conditions, notably $p H$, ratio of reactants, and temperature. The general formation process is a condcnsation of monomeric oxometalates $\left(\mathrm{MoO}_{4}^{2-}, \mathrm{WO}_{4}^{2-}\right)$ in acidic aqueous solution, where protons function as oxygen abstractors in a dehydration process [1]. The reasons for this self-aggregation are far from clear, however, 
as Mo and $W$ are the foremost components in POM compositions, it is undoubtedly due to a beneficial combination of ionic radius, charge and accessibility of $d$-orbitals for metal-oxygen $\pi$-bonding [12]. Kelpert has suggested that the dehydration process accounts for a very favorable entropy change with the formation of more compact structures [7]. Alternatively, other workers [13,14] have made a more quantitative attempt to rationalize the existence and stability of the various structures based on the number of closed loops of $-\mathrm{O}-\mathrm{M}-\mathrm{O}-\mathrm{M}-\mathrm{O}-$ linkages, such as in a triad. The confirmation of $\pi$-bonding character in $\mathrm{M}-\mathrm{O}-\mathrm{M}$ bridges [15] gives chemical credence to this proposal. Since the molybdenum or tungsten atoms are in the highest oxidation state $(+6)$, there are no electrons available for metal-metal binding and the structures are held together by metal-oxygen bonds [4].

\section{Elemental analysis and characterization}

The elemental analysis of polyoxometalates by classical chemical methods has been disturbed by interferences and is a challenge as a routine procedure. There is no question that such analytical difficulties stalled advances in the field in the early 1900's. A useful method must have the accuracy to distinguish between very similar formulations, such as $\mathrm{P}_{2} \mathrm{~W}_{17} \mathrm{O}_{61}^{10-}$ and $\mathrm{P}_{2} \mathrm{~W}_{18} \mathrm{O}_{62}^{6-}$, and the precision to determine the hetcroelements which are in low abundance (less than $1 \%$ to $2 \%$ ) [8]. Polarographic techniques have proven useful for the determination of molybdenum and tungsten in POMs [11,16], however, the central heteroelement concentrations are typically measured by laborious, time consuming gravimetric, titrimetric or colorimetric procedures [1]. With the availability of higher resolution spectrometers and the advances in the stability characteristics of pneumatic nebulizers, inductively coupled plasma-atomic emission spectroscopy (ICP-AES) can be considered as a practical tool for POM analysis. The major limitations of this technique are associated with potential interelement interferences. For example, in the determination of $A s, P, M o$ and $W$ in POM formulations, Fernandez and Bastiaans [17] postulated ionization, physical and spectral types of interferences and described a matrix matching procedure to minimize these problems.

Due to the potential difficulties with chemical analysis, POM composition is best verified by several techniques. The crystal structures of the plenary compounds $\mathrm{II}_{3} \mathrm{PW}_{12} \mathrm{O}_{40} \cdot 5 \mathrm{II}_{2} \mathrm{O}$ and $\mathrm{K}_{10} \mathrm{P}_{2} \mathrm{~W}_{18} \mathrm{O}_{62} \cdot \mathrm{nH}_{2} \mathrm{O}$ were solved by Keggin and Dawson, respectively, and several refinements followed [18]. With structural information, significant advances were enabled in interpretation of many aspects of POM chemistry by a variety of techniques. Raman spectroscopy in $\mathrm{II}_{2} \mathrm{O}$ [19] and IR spectroscopy in $\mathrm{D}_{2} \mathrm{O}$ [15] have been used to fingerprint the polyanion structures in solutions. Correlations between spectral peak positions, shapes, and relative intensities between solid state and solution spectra strongly suggests identical structures [1]. Although, no structural information is available from polarography and cyclic voltammetry, the reduction potentials are useful for "fingerprint" characterization, especially in differentiating between isomers [8]. Studies using ${ }^{183} \mathrm{~W}$ NMR were valuable to elucidate the defect nature of the lacunary structure of $\mathrm{K}_{8} \mathrm{SiW}_{11} \mathrm{O}_{39} \cdot 12 \mathrm{H}_{2} \mathrm{O}$ because the structures could not be solved by X-ray crystallography due to the disorder imposed in the crystalline state by the random 
distribution of the defect site at any of the twelve possible positions [20]. Relevant nuclei of value to POM NMR studies are: ${ }^{1} \mathrm{II},{ }^{17} \mathrm{O},{ }^{51} \mathrm{~V},{ }^{93} \mathrm{Nb},{ }^{95} \mathrm{Mo},{ }^{181} \mathrm{Ta},{ }^{183} \mathrm{~W}$ and also ${ }^{11} \mathrm{~B},{ }^{13} \mathrm{C},{ }^{19} \mathrm{~F},{ }^{27} \mathrm{Al},{ }^{29} \mathrm{Si},{ }^{51} \mathrm{P}$, and ${ }^{59} \mathrm{Co}[1,21]$.

\section{Complexation of metal ions}

Polyoxometalates can bind metal cations via surface terminal and bridging oxygens (e.g. plenary structures) or by enclosing them in a defect site (e.g. lacunary structures) [12]. Examples of the first type are weak and labile complexes of $\mathrm{Eu}$ (III) or $\mathrm{Mn}(\mathrm{II})$ with $\left[\left(\mathrm{H}_{2}\right) \mathrm{W}_{12} \mathrm{O}_{40}\right]^{6-}$ in which monodentate ligands bind through a single terminal oxygen. There are numerous examples of the second type which occurs through the four exterior oxygens that define the defect site of lacunary derivatives [12]. Transition metals are small enough to be enclosed in the vacant site and are isolated as 1:1 complexes, with solvent molecules completing the coordination sphere (e.g. $\left.\left[\left(\mathrm{SiW}_{11} \mathrm{O}_{39}\right) \mathrm{Co}\left(\mathrm{H}_{2} \mathrm{O}\right)\right]^{6-}\right)$. However, lanthanides and actinide ions, with their larger ionic radii and higher charge densities, have been isolated as the 1:2 complexes in which the lanthanide is sandwiched between the defect site of two ligands, such as in $\left[\mathrm{Pr}\left(\mathrm{SiW}_{11} \mathrm{O}_{39}\right)_{2}\right]^{13-}$. The results of investigations of the lanthanide-polyoxometalates are briefly reviewed in the next section.

\subsection{Solid state structures}

The sandwich complexes, first proposed by Peacock and Weakley [22] based on stoichiometry and IR spectra, were confirmed by X-ray investigation of $\mathrm{Cs}_{12}\left[\mathrm{U}\left(\mathrm{GeW}_{11} \mathrm{O}_{39}\right)_{2} \cdot 14 \mathrm{II}_{2} \mathrm{O}, \mathrm{K}_{16}\left[\mathrm{Ce}\left(\mathrm{P}_{2} \mathrm{~W}_{17} \mathrm{O}_{61}\right)_{2}\right] \cdot 50 \mathrm{H}_{2} \mathrm{O}\right.$ and $\mathrm{Ce}\left(\mathrm{W}_{5} \mathrm{O}_{18}\right)_{2}^{9-}[23]$. In these complexes, both uranium and cerium were coordinated to the two ligands via 4 oxygen atoms each in an approximate square anti-prismatic configuration. The lacunary ligands retained the features of the parent Keggin and Dawson structures with very little distortions. An increase in the $\mathrm{Ce}-\mathrm{W}$ distance was observed with higher formal charges on the ligands (for example, in the Ce(III) sandwich complex of $\mathrm{W}_{5} \mathrm{O}_{18}^{6-}$ the $\mathrm{Ce}-\mathrm{W}$ bond length is 3.79 , while in the sandwich complex of $\mathrm{P}_{2} \mathrm{~W}_{17} \mathrm{O}_{61}^{10-}$ it is 3.98).

\subsection{Solution structures}

The aqueous solution structures of $\operatorname{Ln}(\mathrm{POM})_{2}$ were evaluated by several research groups although no accurate stability constants have been reported [1]. Peacock and Weakley $[22,24,25]$ used UV-Vis spectroscopy to approximate the values of the $1: 1$ and $1: 2$ formation constants of $\mathrm{Ce}(\mathrm{III})$ with $\mathrm{PW}_{11} \mathrm{O}_{39}^{7-}$ (as $\log \beta_{1}=$ $6.17 \pm 0.22$ and $\log \beta_{2}=10.18 \pm 0.38$ ). The same research group calculated oscillator strengths for Ln-POMs giving additional support for aqueous complexation. Other researchers [26] used absorption spectroscopy to confirm the formation of 1:1 and $1: 2$ complexes of $\mathrm{Ce}(\mathrm{III})$ with $\mathrm{X}^{n+} \mathrm{W}_{11} \mathrm{O}_{39}^{(12-n)-}(\mathrm{X}=\mathrm{P}, \mathrm{Si}, \mathrm{Ge}, \mathrm{B})$ and $\mathrm{P}_{2} \mathrm{~W}_{17} \mathrm{O}_{61}^{10-}$. Also, this series of complexes was studied by electrochemical methods (cyclic and differential pulse voltammetry) in which the Ce(IV/III) redox potential is a function of the negative charge of the ligand and the ratio of the $\mathrm{Ce}(\mathrm{IV})$ and $\mathrm{Ce}(\mathrm{III})$ stability constants. In the $\mathrm{Ce}$ (III) complexes, the orbital of the 
metal-centered electron is destabilized by coordination of the negatively charged ligand by $\sigma$-donation and the electrostatic effect. Therefore, complexation of one or more ligands generates a cathodic shift in the oxidation potential. Fedotov et al. used ${ }^{31} \mathrm{P}$ NMR to study the formation of $\operatorname{Ln}\left(\mathrm{PW}_{11} \mathrm{O}_{39}\right)_{2}^{11-}$ [27]. At high ligand-to-metal ratio, only one peak assigned to the sandwich complex was observed. At low ligand to metal ratio, two peaks were observed and assigned to free $\mathrm{PW}_{11} \mathrm{O}_{39}^{7-}$ and $\mathrm{Ln}\left(\mathrm{PW}_{11} \mathrm{O}_{39}\right)_{2}$, with no observation of the intermediate 1:1 complex. Alternatively, the chemical shift of the 1:1 complex may be coincident with the chemical shift of the free ligand, and accordingly, both 1:1 and 1:2 complexes are the species present.

\section{Complexation of lanthanide ions}

\subsection{Spectroscopic studies}

Lanthanide ion absorption (in the UV-visible and the near IR region) and luminescence are characterized by narrow bands which are ascribed to internal transitions within the $4 f$ shell (i.e. $f \rightarrow f$ transitions) [28] and, since $\Delta l=0$, are Laporte forbidden. For $d \rightarrow d$ transitions this selection rule is relaxed by distortion of the symmetry about the metal ion due to ligand field effects. However, $4 f$ electrons are buried within the inner electron core and symmetry distortion upon bonding is minimal. Therefore, $f \rightarrow f$ transitions are weaker and sharper than $d \rightarrow d$ transitions and the ligand field effect is considerably smaller.

Hypersensitive transitions (the $f \rightarrow f$ transitions in which the absorption maximum and intensity are sensitive to the ligand field) were used to evaluate the site symmetry and nephelauxetic effect of the lanthanide-polyoxometalate sandwich complexes, $\mathrm{Ln}(\mathrm{POM})_{2}$ [29]. In each ligand, the oxygens of the binding site approximately define a square. In the sandwich complex, the two square binding sites are superimposed to give either an eclipsed (point group $D_{4 h}$ ) or an staggered (point group $D_{4 d}$ ) arrangement. Evaluation of the splitting of ${ }^{7} F_{0} \rightarrow{ }^{5} D_{2}$ and ${ }^{7} F_{0} \rightarrow{ }^{5} D_{1}$ excitation bands in Ln-POM complexes indicates their low symmetry. Unsaturated polyanions such as $\mathrm{SiW}_{11} \mathrm{O}_{39}^{8-}$ exhibit a ligand field strength distinctly weaker than $\mathrm{II}_{2} \mathrm{O}$ [30]. Furthermore, due to the weak nature of $f \rightarrow f$ transitions, the sensitivity of absorption measurements are limited.

Some members of the lanthanide series have certain excited states which are capable to relax by emission of photons. While such electronic transitions within a $4 f^{n}$ configuration are still Laporte forbidden, an intense laser beam can be used as an excitation source to access the excited state and monitor its luminescence decay quantitatively even in dilute solutions. This process is called laser-induced lanthanide ion luminescence and it has been developed and exploited as a probe for biological system [31].

The excited state lifetime is efficiently quenched by $\mathrm{OH}$ oscillators of inner sphere $\mathrm{II}_{2} \mathrm{O}$ molecules bound to the $\mathrm{Eu}(\mathrm{III})$ ion. The difference in the decay of the excited state in $\mathrm{I}_{2} \mathrm{O}$ and $\mathrm{D}_{2} \mathrm{O}$ is proportional to the number, $n$, of water molecules coordinated to the first coordination sphere as described by the equation proposed by Horrocks and Sudnick [32]:

$$
n=1.05\left[k\left(\mathrm{I}_{2} \mathrm{O}\right)-k\left(\mathrm{D}_{2} \mathrm{O}\right)\right] \text {, }
$$


where $k\left(\mathrm{H}_{2} \mathrm{O}\right)$ and $k\left(\mathrm{D}_{2} \mathrm{O}\right)$ are the exponential decay constants for the luminescence intensity of the excited states in $\mathrm{I}_{2} \mathrm{O}$ and $\mathrm{D}_{2} \mathrm{O}$, respectively. The uncertainty has been estimated as $\pm 0.5 \mathrm{II}_{2} \mathrm{O}$ molecules. Using this technique, Ballardini et al. [33] found no inner sphere $\mathrm{II}_{2} \mathrm{O}$ s in $\mathrm{Eu}\left(\mathrm{BW}_{11} \mathrm{O}_{39}\right)_{2}^{15-}$ and $\mathrm{Eu}\left(\mathrm{SiW}_{11} \mathrm{O}_{39}\right)_{2}^{13-}$ in aqueous solution or the solid state while the $1: 1$ complexes had 4 inner sphere $\mathrm{H}_{2} \mathrm{Os}$ in aqueous solution. High resolution analysis of the number of bands observed in the emission spectra for the ${ }^{7} F_{\mathrm{J}} \rightarrow{ }^{5} D_{0}$ transitions supports the hypothesis of low symmetry [33].

${ }^{7} F_{0} \rightarrow{ }^{5} D_{0}$ selective excitation spectroscopy of $E u(I I I)$. The $4 f^{6}$ electronic configuration of $\mathrm{Eu}$ (III) has a nondegenerate ground state, ${ }^{7} F_{0}$ and a nondegenerate long-lived emitting state, ${ }^{5} D_{0}$. In other words, neither the ground state nor the emissive state are split by the ligand field. The Eu(III) ion may be selectively excited by tuning a dye laser to the energy of the ${ }^{7} F_{0} \rightarrow{ }^{5} D_{0}$ in the 578 to $581 \mathrm{~nm}$ region and the emission can be monitored at $615 \mathrm{~nm}$. The multiplet excitation to higher ${ }^{5} D_{i}$ states is followed by a rapid decay to the long-lived ${ }^{5} D_{0}$ state. The consequence of this unique feature of the $0-0$ transition is that in the excitation spectrum of a metal complex, the number of peaks observed directly corresponds to the number of $\mathrm{Eu}$ (III) environments present in solution [34].

Among many heteropolytungstate anions there are two compositions $\left[\mathrm{NaSb}_{9} \mathrm{~W}_{21} \mathrm{O}_{86}\right]^{18-}$ and $\left[\mathrm{NaP}_{5} \mathrm{WO}_{30} \mathrm{O}_{110}\right]^{14-}$ (the Preyssler anion) that encapsulate lanthanide ions [35-37]. The significance and wide interest of these lanthanide-encrypted anions concerns their potential antiviral activity and applications in catalysis [36]. The $\left[\mathrm{NaP}_{5} \mathrm{~W}_{30} \mathrm{O}_{110}\right]^{14-}$ anion consists of five $\mathrm{PW}_{6} \mathrm{O}_{22}$ units (derived from the Keggin anion $\left[\mathrm{PW}_{12} \mathrm{O}_{40}\right]^{3-}$ ) arranged in a crown to form a cylindrical cavity. The $\mathrm{Na}^{+}$ion in the Preyssler anion is asymmetrically encapsulated within this cavity and can be replaced by trivalent rare earth ions.

In our study the Preyssler heteropolyanion $\left[\mathrm{NaP}_{5} \mathrm{~W}_{30} \mathrm{O}_{110}\right]^{14-}$ and its europium-encrypted hetcropolyanion $\left[\mathrm{EuP}_{5} \mathrm{~W}_{30} \mathrm{O}_{110}\right]^{12-}$ were spectroscopically characterized using absorption and luminescence spectra as well as results of the laser-induced europium ion luminescence spectroscopy recorded for solid complexes and their solutions [38]. It was found three water molecules in the inner sphere of $\mathrm{Eu}$ (III) in the europium-encapsulated complex in aqueous solution and in the solid state. The gadolinium-encrypted Preyssler anion $\left[\mathrm{GdP}_{5} \mathrm{~W}_{30} \mathrm{O}_{110}\right]^{12-}$, and gadolinium sandwiched (between the defect site of two ligands) complex, such as $\left[\mathrm{Gd}\left(\mathrm{SiW}_{11} \mathrm{O}_{39}\right)_{2}\right]^{12-}$, we selected for EPR study [39].

\subsection{Mechanism of contrasl agent enhancement}

With the exception of $\mathrm{La}$ and $\mathrm{Lu}$, the umpaired electrons of the lanthanides in the $3+$ oxidation state make them paramagnetic and some exhibit very large magnetic moments, $\mu_{\mathrm{B}}$. Gadolinium(III) has an electronic configuration $[\mathrm{Xe}] 4 f^{7}$ (Xe is the xenon electronic configuration). With the half-filled $f$-shell, there are 7 unpaired electrons $(S=7 / 2)$ which generate the largest magnetic moment and thus, the highest paramagnetic character in the series. The relaxivity of $1 \mathrm{mM}$ $\mathrm{Gd}^{3+}$ is $9.1 \mathrm{mM}^{-1} \mathrm{~s}^{-1}\left(20 \mathrm{MIIz}, 35^{\circ} \mathrm{C}\right)$ but this is largely attenuated upon complexation to a ligand (for example, Grl(DTPA) ${ }^{2-}$ has a relaxivity of $4.1 \mathrm{mM}^{-1} \mathrm{~s}^{-1}$ ) under the same conditions. 
The properties of the lanthanide (III) ions usually vary in a regular manner from La to Lu. Nearest neighbors, therefore, have the most similar properties and can be expected to behave quite similarly. While Gd(III) is the ion of interest to magnetic resonance imaging magnetic resonance imiging (MRI) with an ionic radius of $93.8 \mathrm{pm}$, its nearest neighbor, $\mathrm{Eu}(\mathrm{III})$, is of comparable size with an ionic radius of $94.7 \mathrm{pm}$ and can be used as an analogue for $\mathrm{Gd}(\mathrm{III})$. In this manner, the special properties of $\mathrm{Eu}$ (III) can be utilized to deduce information about $\mathrm{Gd}$ (III) chemistry.

Contrast agents have expanded the utility of MRI by helping to distinguish between normal and pathological conditions such as tumors and tissue damage. The NMR signal observed is characterized by three basic parameters: the proton spin density $(\rho)$, and the relaxation times $T_{1}$ and $T_{2} . T_{1}$, the longitudinal (or spin-lattice) relaxation time, is the exponential time constant that describes the relaxation of the component of magnetization along the $z$-axis back to its equilibrium position. Similarly, $T_{2}$, the transverse (or spin-spin) relaxation time, is the exponential time constant that describes the relaxation of the component of magnetization along the $x-y$ plane back to its equilibrium position. The basis of image enhancement using paramagnetic agents is the dependence of ${ }^{1}$ II NMR image intensity on these tissue relaxation times [40]. The intensity derives from the local magnetic fields of paramagnetic substances which cause them to act as relaxation centers for other nuclei in their immediate vicinity. The relaxation process is characterized by shortening of proton relaxation times to provide improved tissue contrast, depending on their biodistribution.

\subsection{General requirements for use of gadolinium complexes as magnetic resonance imaging agents}

Metal complex MRI contrast agents have been developed predominantly around gadolinium(III) due to its large magnetic moment and its ability to form stable complexes with a variety of ligands. Most attention has been devoted to organic ligands for complexing gadolinium due to the high stability constants, high relaxivities $\left(R=1 / T_{1 \mathrm{e}}\right)$, and some target specificity [41]. Complexes such as $\mathrm{Na}_{2} \mathrm{Gd}(\mathrm{DTPA})\left(\mathrm{II}_{2} \mathrm{O}\right)$ decrease the electronic relaxation time $\left(T_{1 \mathrm{e}}\right)$ of nearby proton nuclei resulting in an enhancement of image intensity at that site. However, polyoxometalates are purely inorganic compounds which offer attractive features as

\section{TABLE II}

Desirable properties of contrast imaging agents.

\begin{tabular}{l|l}
\hline \hline \multicolumn{1}{c|}{ Safety features } & \multicolumn{1}{c}{ Efficacy features } \\
\hline Low toxicity & Optimum magnetic moment, $\mu_{\mathrm{B}}$ \\
Neutral and stable & $\begin{array}{l}\text { Sufficient } \mathrm{II}_{2} \mathrm{O} \text { solubility } \\
\text { Optimum number of } \mathrm{H}_{2} \mathrm{O} \text { in the inner } \\
\text { Low viscosity } \\
\text { Acceptable osmolarity }\end{array}$ \\
$\begin{array}{l}\text { A sufficiently low ion to nucleus ratio: } \\
\text { dipolar interaction } 1 / r^{6}\end{array}$
\end{tabular}


gadolinium ligands. Such complexes have potential applications in imaging and/or nuclear medicine. A list of desirable characteristics is presented in Table II. Although no agent possesses all of them, they can be classified into safety and efficacy (efliciency) features.

\section{Biological studies}

\subsection{Antiviral activity}

The antiviral activity of polyoxometalates has been known for over 20 years. The first compound to receive serious attention as an antiviral and anti-IIIV agent was HPA-23, $\left(\mathrm{NH}_{4}^{+}\right)_{17}\left(\mathrm{Na}^{+}\right)\left[\mathrm{NaW}_{21} \mathrm{Sb}_{9} \mathrm{O}_{86}^{18-}\right],[42]$ although its value was limited by toxic side effects in clinical trials [43]. However, a valuable development was the demonstration of two mechanisms of polyoxometalate inhibition of HIV activity [44]. First, POMs are potent inhibitors of IIIV reverse transcriptase, which is fundamental to the retrovirus life cycle. Second, and more importantly, they inhibit binding of infected lymphocytes with healthy uninfected cells [42]. This second mode of action is believed to be a potentially significant direction for future treatment of AIDS.

With possibly thousands of polyoxometalate formulations to choose from, Hill et al. [44] selected 38 representative compounds to evaluate the structure-activity relationship for both toxicity and anti-IIIV activity. The results indicate that anti-HIV activity is a common feature of $80 \%$ of these compounds although their degree of effectiveness varies. In general, the toxicity was found to vary widely with a significant dependence on the cationic counter ions. For example, the $\mathrm{NII}^{4+}$ salts were less toxic than the $\mathrm{K}^{+}, \mathrm{Na}^{+}$or $\mathrm{II}^{+}$salts without compromise of antiviral activity. Compounds with smaller sizes and charge densities, such as $\mathrm{W}_{6} \mathrm{O}_{19}^{2-}$, were generally ineffective as antiviral agents. Only POMs with large sizes (at least $12 \mathrm{~W}$ atoms) had a considerable effect.

\section{References}

[1] M.T. Pope, Heteropoly and Isopolymetalates, Springer-Verlag, New York 1983.

[2] A.D. Kirk, W. Riske, D.K. Lyon, B. Rapko, R.G. Finke, Inorg. Chem. 28, 792 (1989).

[3] M.T. Pope, B.W. Dale, Quart. Rev. Chem. Soc. 22, 527 (1968).

[4] V.W. Day, W.G. Klemperer, Science 228, 4699 (1985).

[5] L.C.W. Baker, L. Lebioda, J. Grochowski, II.G. Mukherjee, J. Am. Chem. Soc. 102, 3274 (1980).

[6] D.E. Katsoulis, M.T. Pope, J. Am. Chem. Soc. 106, 2737 (1984).

[7] D.L. Kelpert, Inorg. Chem. 8, 1556 (1969).

[8] C. Rocchiccioli-Deltcheff, M. Fournier, R. Franck, R. Thouvenot, Inorg. Chem. 22, 207 (1983).

[9] G. Chidichmo, A. Golemme, D. Imbardelli, A. Iannibello, J. Chem. Soc. Faraday Trans. 188, 483 (1992).

[10] J. Martin-Fère, Y. Jeaunin, F. Robert, J. Vaissermann, Inorg. Chem. 30, 3635 (1991).

[11] A. Tézé, G. Hervé, J. Inorg. Nucl. Chem. 39, 999 (1977).

[12] M.T. Pope, A. Müller, Angew. Chem. Int. Ed. Engl. 30, 34 (1991).

[13] K. Nomiya, M. Miwa, Polyhedion 3, 341 (1984). 
[14] K. Nomiya, Polyhedron 6, 309 (1979).

[15] W.G. Klemperer, W. Shuin, J. Am. Chem. Soc. 98, 8291 (1976).

[16] M.T. Pope, G.M. Varga, Inorg. Chem. 5, 1249 (1966).

[17] M.A. Fernandez, G.J. Bastiaans, Anal. Chem. 51, 1402 (1979).

[18] H. D'Amor, Acta Crystallogr. B 32, 729 (1976).

[19] J. Aveston, Inorg. Chem. 3, 981 (1964).

[20] K.Y. Matsumoto, Y. Sasaki, Bull. Chem. Soc. Japan 49, 156 (1976).

[21] P.L. Rinaldi, G.C. Levy, G.R. Choppin, Rev. Inorg. Chem. 2, 53 (1980).

[22] R.D. Peacock, T.J.R. Weakley, J. Chem. Soc. A 1836 (1971).

[23] V.N. Molchanov, L.P. Kazanskii, E.A. Torchenkova, V.I.Simonov, Sov. Phys. Crystallogr. 24, 96 (1979).

[24] J. Iball, J.N. Low, T.J.R. Weakley, J. Chem. Soc. Dalton Trans. 2121 (1974).

[25] T.J.R. Weakley, S.A. Malik, J. Chem. Soc. A 2647 (1968).

[26] N. Haraguchi, Y. Okane, T. Isobe, Y. Matsuda, Inorg. Chem. 33, 1015 (1994).

[27] M.A. Fedotov, B.Z. Pcrisikov, D.K. Danovich, Polyledron 9, 1249 (1990).

[28] W.T. Carnall, in: IIandbook on the Physics and Chemistry of Rare Earths, Eds. K.A. Gschneidner, L.R. Eyring, Vol. 3, North-Holland, Amsterdam 1979, p. 171.

[29] R.D. Peacock, T.J.R. Weakley, J. Chem. Soc. A 1937 (1971).

[30] C.M. Tourné, G. Tourné, S.A. Malik, T.J.R. Weakley, J. Inorg. Nucl. Chem. 32, 3875 (1970).

[31] J.-C.G Bünzli, in: Lanthanide Probes in Life, Chemical and Earth Sciences. Theory and Practice, Eds. J.-C.G Bünzli, G.R. Choppin, Elsevier, New York 1979, Ch. 7.

[32] W.De W. Torrocks, D.R. Sudnick, J. Am. Chem. Soc. 101, 334 (1979).

[33] R. Ballardini, E. Cliorboli, V. Balzani, Inorg. Chim. Acta 95, 323 (1984).

[34] M. Albin, G.K. Faber, W.DeW. Horrocks, Inorg. Chem. 23, 1648 (1984).

[35] I. Creaser, M.C. Heckel, R.J. Neitz, M.T. Pope, Inorg. Chem. 32, 1573 (1993).

[36] M.R. Antonio, L. Soderholm, Inorg. Chem. 33, 5988 (1994).

[37] L. Soderholın, G.K. Liu, J. Muntean, J. Malinsky, M.R. Antonio, J. Phys. Chem. 09, 9611 (1995).

[38] S. Lis, M. Elbanowski, S. But, Acta Phys. Pol. A 90, 361 (1996).

[39] A. Szyczewski, S. Lis, Z. Kruczyniski, J. Pietrzak, S. But, M. Elbanowski, Acta Phys. Pol. A 90, 345 (1996).

[10] R.B. Lauffer, Chem. Rev. 87, 901 (1987).

[41] M.F. Tweedle, in: Lanlhanide Probes in Life, Chemical and Earth Sciences. Theory and Practice, Eds. J.-C.G Büuzli, G.R. Choppin, Elsevier, New York 1979, Chap. 5.

[42] J. Fisher, L. Richard, R. Weiss, J. Am. Chem. Soc. 106, 7274 (1976).

[43] F. Burgard, P. Sansonnetti, D. Vittecoq, P. Descamps, D. Guetard, S. Herson, W. Rozenbaum, C. Rouzioux, AIDS 3, 665 (1989).

[44] C.L. Hill, M. Hartuup, M. Faraj, M. Weeks, C.M. Prosser-McCartha, R.B. Brown Jr., M. Kadkhodayan, J.-P. Sommadossi, R.F. Sclinazi, Advances in Chemotherapy of Aids 33 (1990). 